\title{
Investigation of Polishing Characteristics for Aspherical Lenses Manufacturing
}

\author{
Nerijus KADZEVIČIUS*, Ieva ŠVAGŽDYTEં**, Justinas GARGASAS***, \\ Mindaugas JUREVIČIUS****, Artūras KILIKEVIČIUS***** \\ *Vilnius Gediminas Technical University, J. Basanavičius St. 28, LT-03224, Vilnius, Lithuania, \\ E-mail: nerijus.kadzevicius@gmail.com \\ **Vilnius Gediminas Technical University, J. Basanavičius St. 28, LT-03224, Vilnius, Lithuania, \\ E-mail: ieva.svagzdyte@vgtu.lt \\ ***Vilnius Gediminas Technical University, J. Basanavičius St. 28, LT-03224, Vilnius, Lithuania \\ E-mail: justinas.gargasas@vgtu.lt \\ ****Vilnius Gediminas Technical University, J. Basanavičius St. 28, LT-03224, Vilnius, Lithuania, \\ E-mail: mindaugas.jurevicius@vgtu.lt \\ *****Vilnius Gediminas Technical University, J. Basanavičius St. 28, LT-03224, Vilnius, Lithuania, \\ E-mail: arturas.kilikevicius@vgtu.lt
}

cross $^{\text {ref }}$ http://dx.doi.org/10.5755/j01.mech.26.5.24572

\section{Introduction}

Fabrication of optical elements by machining results in surface irregularities and a certain roughness. Any manufacturing inaccuracies damage the entire operation of the optical system due to excessive form deviations, light, or laser beam propagated through a lens, prism or other optical element that can cause distortion, image irregularity, or system damage in the worst case, and this is especially true for high power lasers. If the optical surface has mechanical damage (lines, cracks, etc.), it causes additional resistance to the laser beam, in which case heat is released in the areas where the damage occurs, rendering the entire system unusable and unsafe. All of the shortcomings listed above occur due to inadequate technological parameters during the manufacture process, as well as installation inaccuracies, measurement errors, in-process tool wear and other factors. It is important to examine what technological parameters would reduce the resulting inaccuracies during manufacturing, as the most difficult operation in the production of aspherical lenses is polishing.

Spherical lenses were used in conventional industry for a long time, but new types of lenses have been created during the innovation processes. One type of lenses is the aspherical ones. They allow to reduce the number of lenses in optical systems, are thinner and exhibit better optical characteristics. The demand of lenses of this type is constantly increasing (they are used in cameras, lasers and other optical systems); and it is a problem to optimize the manufacturing process for aspherical lenses.

Various parameters are important to control the polishing process if it is necessary to get high quality of the optical element. Two main parameters describing the quality of aspherical lenses are accuracy of the form shape and surface roughness. Small surface roughness secures good optical transmittance [1]. The size of abrasive grains makes the biggest influence on the surface. The workpieces of SiC were investigated in a step-terrace structure after polishing, where a smaller surface roughness was established with small abrasive grains [2]. Rotation speed, polishing pressure and time had the influence on the polishing process. When the polishing pressure increases, the coefficient of friction also increases [3]; and when the rotation speed and size of abrasive grains increases, the surface roughness deteriorates [4-7].

Cerium oxide pellets [8] or soft-magnetic particles with magnetorheological fluid [9] could be used to make the polishing process more effective, yet these technologies can cause trouble in $\mathrm{CNC}$ polishing machining. The elastic properties of the pad material change in the polishing time, but they do not have the main influence on the surface quality [10]. It is more important to keep necessary accuracy between the polisher and the workpiece [11].

A semi-rigid bonnet tool and penetration depth control were used to get the form shape of aspherical lenses [12 - 14] that is important for the optical characteristics. A research on the polishing characteristics for aspherical lenses from fused quartz manufacturing has been conducted and optimal polishing parameters for the best quality of aspherical lenses are provided in this article.

\section{Object of the research}

Aspherical lenses of $25.4 \mathrm{~mm}$ in diameter with a focal length of $F=60 \mathrm{~mm}$ were selected for the test. Such lenses were chosen because of their complexity of manufacture, which is strongly convex and requires the machine to make much longer movements, which results in greater errors. Such short-focal aspherical lenses often used to optimize their polishing rates is the aim of this research.

The geometric parameters of manufacturing aspherical lenses were described by the formula (1):

$$
z=\frac{Y^{2}}{R\left(1+\sqrt{1-(1+k) \frac{Y^{2}}{R^{2}}}\right)}+A_{4} Y^{4}+A_{6} Y^{6}+\ldots+A_{n} Y^{n}
$$

where: $A_{4}, A_{6}, A_{n}$ are coefficients; $Y$ is coordinate from the center of lens; $z$ is height of camber ( 0 in the center, maximum at the edge) $k$ is conicality; $R$ is radius of curvature.

Aspherical lenses parameters chosen for the experimental data are demonstrated in Fig. 1. 


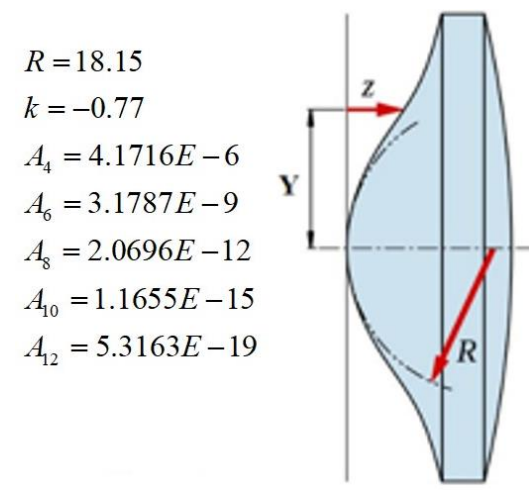

Fig. 1 Aspherical lens

Fused quartz specimens were chosen for the experiments because they are one of the most widely used materials in optics, and hardly any research has been performed with the exception of BK7.

\section{The experimental setup}

The mechanical processing of lenses consists of cutting, profiling to the necessary diameter, grinding and polishing. The spherical shape was manufactured in the first grinding operation with CNC grinding machine, whereas the aspherical shape was manufactured in the second grinding operation. The polishing process consisted of two operations. A clear surface was obtained in the first polishing operation, while in the second, a necessary form shape was received. The measurements and the appreciated quality were obtained after manufacturing. The polishing process could be repeated if necessary.

The technology of aspherical lense manufacturing from melted quartz was investigated. A cylindrical workpiece with the diameter of $25.4 \mathrm{~mm}$ is presented in Fig. 2. The five-axis CNC machine Schneider "SCPA100" (maximum rotation speed $2500 \mathrm{rpm}$ ) was used for polishing, and the diameter of toll was $100 \mathrm{~mm}$.

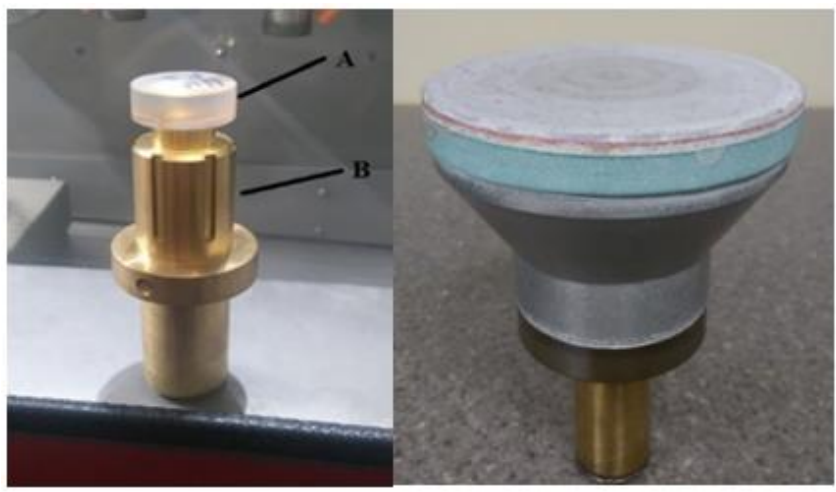

a

b

Fig. 2 Cylindrical workpiece a) $A$ glued up on the holder $B$; b) polisher on the right side

The polishing scheme is shown in Fig. 3. The polisher was turned into direction $\mathrm{B}$ and the workpiece - into direction $\mathrm{C}$. Moving axes $\mathrm{Z}, \mathrm{X}$ and $\mathrm{C}$ guaranteed a fixed contact between the polisher and the workpiece in the different places on the lens. The polisher was made from a metallic part and polyurethane, which was penetrated into the workpiece at $0.1-0.3 \mathrm{~mm}$ depth.

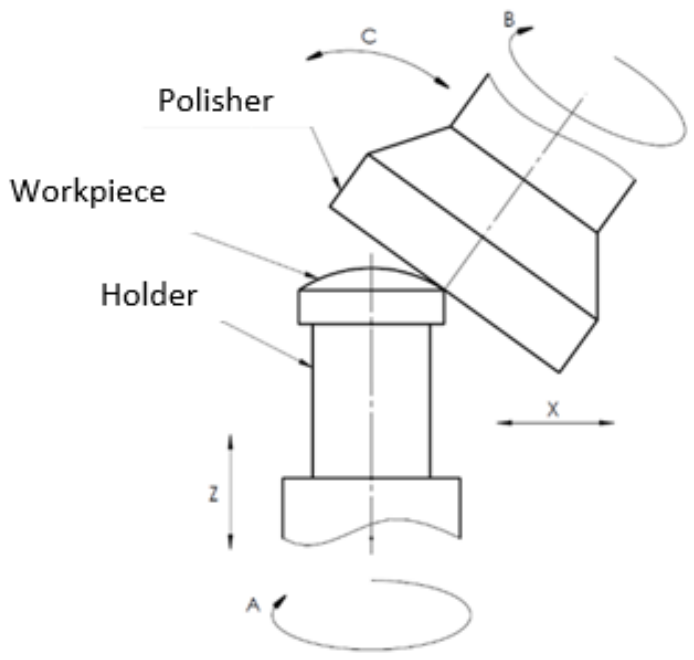

Fig. 3 Polishing scheme for aspherical lenses

The form shapes were measured after each polishing operation with the profilometer "Hommel Etamic Nanoscan 855", which is demonstrated in Fig. 4. The measured profile was automatically compared to the theoretical profile, whereas the surface roughness was appreciated, too. The data provided were processed using the custom software "Turbo Wave". It described the ideal theoretical curve with which the real profile was compared after polishing; the measuring distance and the number of points were selected. The most commonly used parameter for measurement of optical element deflection, which is usually designated as PV peak-to-valley, is the distance of deviation from minimum to maximum.

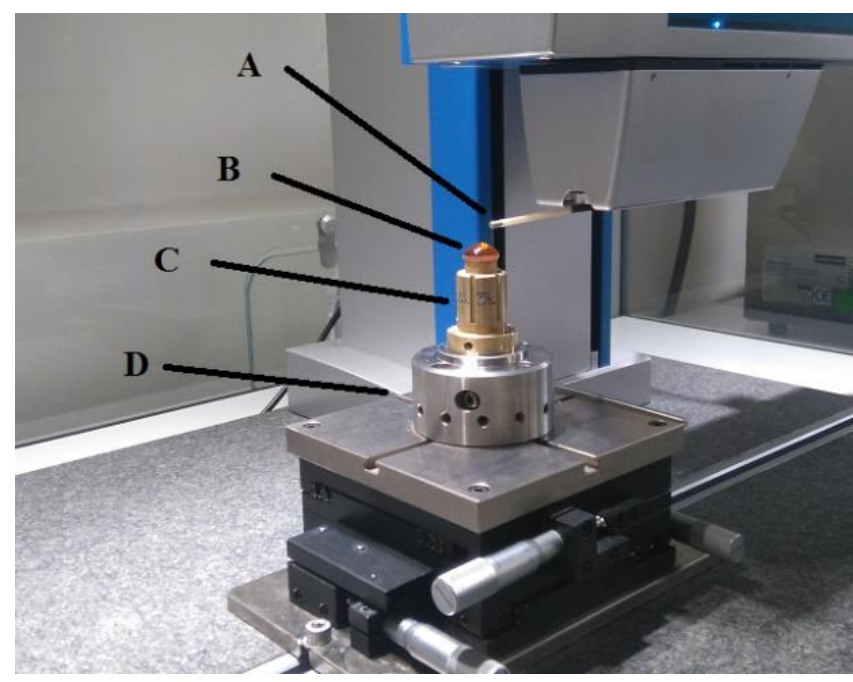

Fig 4 Measuring aspherical lenses with the profilometer; A - probe, B - lens, $\mathrm{C}$ - holder, D - form precision positioning

Surface shape deviation PV was measured with a spherical probe of $1 \mathrm{~mm}$ in diameter. The roughness parameter Rz was measured with the needle tip "WCN1T KE5 / $90 \mathrm{~T} 7.0 \mathrm{D} 11 / 30$ " with a rounding radius of $5 \mathrm{um}$.

The experiment plan for all of the factors (full factorial design) was devised. Investigators can analyze the behavior of the system in different conditions with factors changing at a time. Each size of the test constitutes the numerical result of the range of the factors. Only two factors had the influence on the set of examples as the plan was projected only of two factors (using the formula $2^{f}$, where $f-$ 
number of factors). Three factors made the sides of a cube $3^{2}=9$. If there are more factors, they are projected as the tops of the cube. The experiment plan for all of the factors is the most popular [15]. The factors and levels of the experiment are shown in Table 1.

Table 1

Factors and levels of the experiment plan

\begin{tabular}{|c|c|c|c|c|}
\hline & $\begin{array}{c}\text { Lower } \\
\text { level (-1) }\end{array}$ & $\begin{array}{c}\text { Standard } \\
\text { level (0) }\end{array}$ & $\begin{array}{c}\text { High } \\
\text { level (+1) }\end{array}$ & $\begin{array}{c}\text { Units of } \\
\text { measure }\end{array}$ \\
\hline Polisher speed & 800 & 1000 & 1200 & $\mathrm{rpm}$ \\
\hline $\begin{array}{c}\text { Penetration } \\
\text { depth of the } \\
\text { polisher }\end{array}$ & 0,15 & 0,2 & 0,25 & $\mathrm{~mm}$ \\
\hline
\end{tabular}

The polisher speed and penetration depth of the polisher were chosen as the main factors for the experimental data with reference to manufacturing experience. They are usually replaced during the process of machining to obtain the best quality of the lens. Polishing suspension, temperature and other polishing parameters were recorded. The levels of the factors were chosen with reference to manufacturing experience. It was found that working with the parameters as the chosen ones for the experimental data, the best surface quality was achieved.

Experiments were made using all the combinations of factors and levels.

\section{Results and discussion}

The results and experimental data of measurements are shown in Table 2.

Table 2

Results of measurements

\begin{tabular}{|c|c|c|c|c|}
\hline $\begin{array}{c}\text { Experi- } \\
\text { ment No. }\end{array}$ & $\begin{array}{c}\text { Penetration } \\
\text { dept of pol- } \\
\text { isher, mm }\end{array}$ & $\begin{array}{c}\text { Polisher } \\
\text { speed, rpm }\end{array}$ & $\begin{array}{c}\text { Form } \\
\text { shape devi- } \\
\text { ation, } \mu \mathrm{m}\end{array}$ & $\begin{array}{c}\text { Surface } \\
\text { roughness } \\
R_{z}, \mu \mathrm{m}\end{array}$ \\
\hline 1 & 0.15 & 1200 & 3.4 & 0.066 \\
\hline 2 & 0.15 & 800 & 2.6 & 0.176 \\
\hline 3 & 0.15 & 1000 & 3.2 & 0.081 \\
\hline 4 & 0.2 & 1200 & 4.7 & 0.068 \\
\hline 5 & 0.2 & 800 & 3.1 & 0.088 \\
\hline 6 & 0.2 & 1000 & 3.9 & 0.078 \\
\hline 7 & 0.25 & 800 & 3.3 & 0.09 \\
\hline 8 & 0.25 & 1200 & 6.9 & 0.06 \\
\hline 9 & 0.25 & 1000 & 4.5 & 0.066 \\
\hline
\end{tabular}

Two parameters were measured - form shape deviation (Fig. 5) and surface roughness $R_{z}$. They are most important for getting a good permeability of the ray and focusing it.

Different results of the measurements were obtained, so it is necessary to make their analysis. The analysis of the results presented in Fig. 6 demonstrates that deviation from the form shape decreases when the penetration depth and the rotation speed of the polisher decrease. However, the material removal rate also decreases, so the polishing time becomes longer than working with higher speed and bigger penetration depth.

Surface roughness was appropriated and the results are shown in Fig. 7. When rotation speed and penetration depth increase, surface roughness decreases and the quality of the surface of aspherical lenses increases.

The program "Design Expert 10" was used to appreciate general effectiveness. The results are shown in Fig. 8.

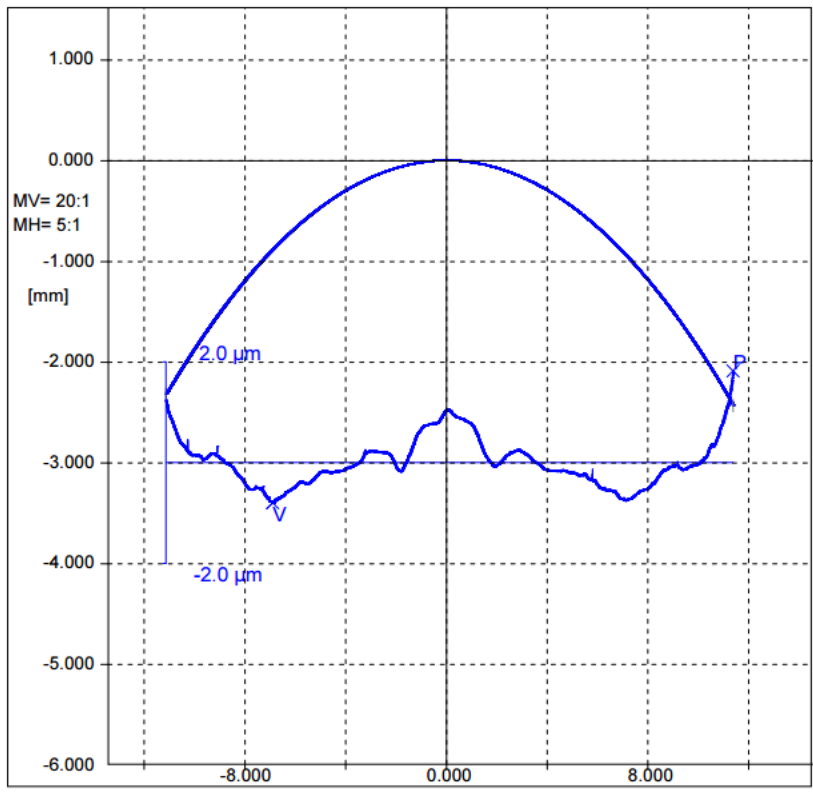

Fig. 5 Example of measurements

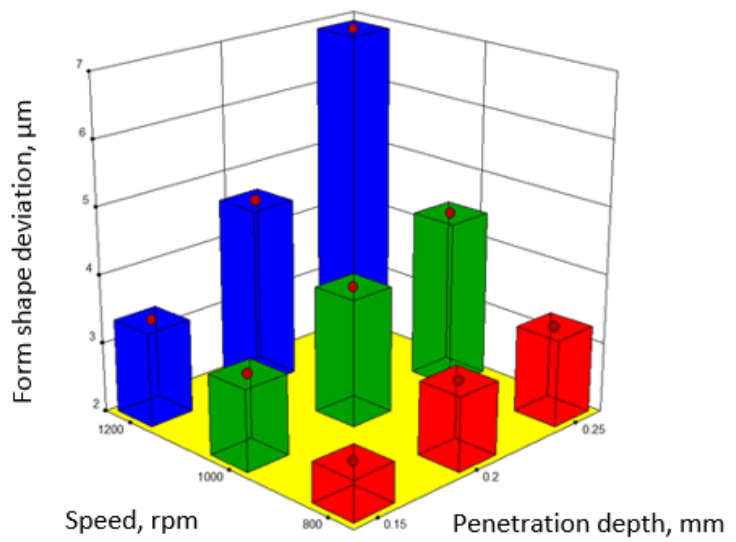

Fig. 6 Influence of form shape deviation on penetration depth and rotation speed

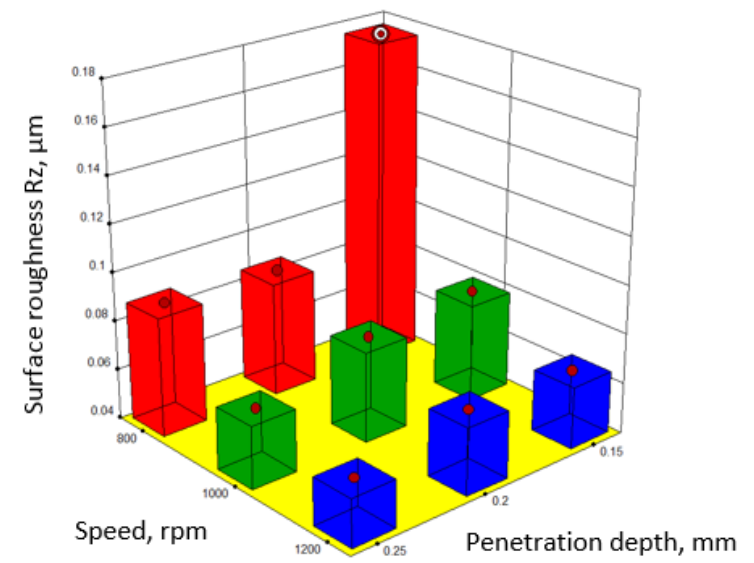

Fig. 7 Influence of surface roughness on penetration depth and rotation speed

It was found that the best simultaneous combination of polishing situation for small surface roughness and form shape deviation is with the penetration depth $0.25 \mathrm{~mm}$ and rotation speed $1000 \mathrm{rpm}$. The effectiveness of all the experiments is shown in Table 3. 


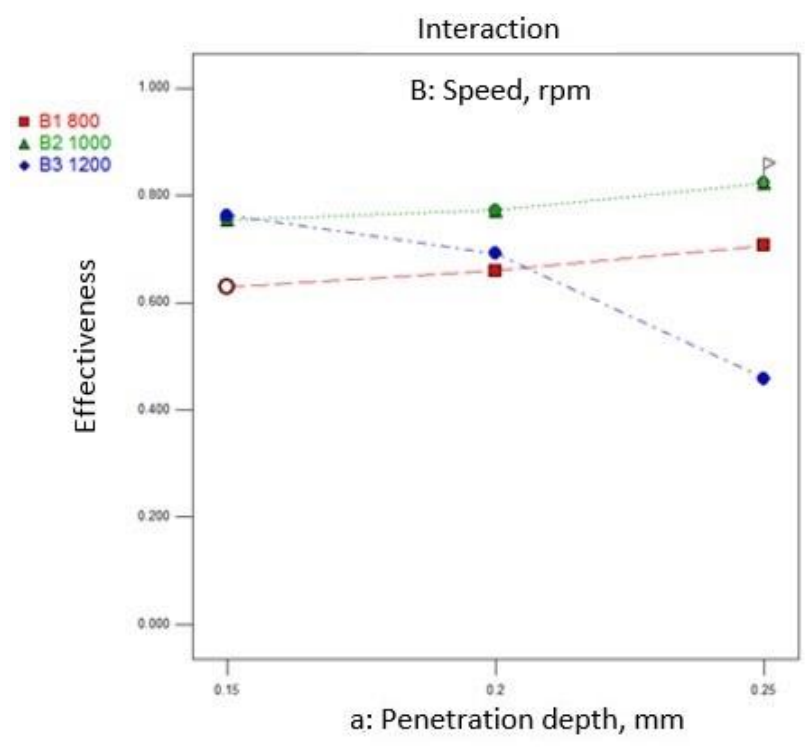

Fig. 8 Graph of effectiveness
The combination of the lowest levels of factors (the polisher speed $800 \mathrm{rpm}$ and the penetration depth of polisher $0.15 \mathrm{~mm}$ ) got 0.630 effectiveness. The combination of the highest levels of factors (polisher speed $1200 \mathrm{rpm}$ and penetration depth of polisher $0.25 \mathrm{~mm}$ ) got only 0.495 effectiveness.

\section{Conclusions}

Penetration depth and polisher rotation speed have the biggest influence on the quality of aspherical lenses. To obtain the best shape, it is necessary to use the smallest chosen values of rotation speed and penetration depth, whereas the parameters for surface roughness polishing change conversely. The smallest value of surface roughness $R z$ was $0.06 \mu \mathrm{m}$, and shape deviation was $2.6 \mu \mathrm{m}$. It was found that the best simultaneous combination of polishing situation for small surface roughness and form shape deviation is with the penetration depth $0.25 \mathrm{~mm}$ and rotation speed $1000 \mathrm{rpm}$.

Effectiveness of experiments

Table 3

\begin{tabular}{|c|c|c|c|c|c|}
\hline $\begin{array}{c}\text { Experiment } \\
\text { No. }\end{array}$ & $\begin{array}{c}\text { Penetration depth, } \\
\mathrm{mm}\end{array}$ & Speed, rpm & $\begin{array}{c}\text { Form shape deviation, } \\
\mu \mathrm{m}\end{array}$ & $\begin{array}{c}\text { Surface roughness } R z, \\
\mu \mathrm{m}\end{array}$ & Effectiveness \\
\hline 1 & $\underline{0.25}$ & $\underline{1000}$ & $\underline{3.556}$ & $\underline{0.075}$ & $\underline{0.823}$ \\
\hline 2 & 0.2 & 1000 & 3.956 & 0.075 & 0.772 \\
\hline 3 & 0.15 & 1200 & 4.289 & 0.065 & 0.763 \\
\hline 4 & 0.15 & 1000 & 4.089 & 0.075 & 0.754 \\
\hline 5 & 0.25 & 800 & 2.356 & 0.118 & 0.707 \\
\hline 6 & 0.2 & 1200 & 4.756 & 0.065 & 0.692 \\
\hline 7 & 0.2 & 800 & 3.156 & 0.118 & 0.660 \\
\hline 8 & 0.15 & 800 & 3.489 & 0.118 & 0.630 \\
\hline 9 & 0.25 & 1200 & 5.956 & 0.065 & 0.459 \\
\hline
\end{tabular}

\section{References}

1. Lee, J. W.; Cho, Y. K.; Cho, M. W.; Kim, G. H.; Je, T. J. 2012. Optical transmittance recovery of powder blasted micro fluidic channels on fused silica glass using MR polishing, International Journal of Precision Engineering and Manufacturing 13-11: 1925-1930. http://dx.doi.org/10.1007/s12541-012-0254-5.

2. Shi X.; Pan G.; Zhou Y.; Gu Z.; Gong H.; Zou C. 2014. Characterization of colloidal silica abrasives with different sizes and their chemical-mechanical polishing performance on 4H-SiC (0 00 1), Applied Surface Science 307: 414-427.

http://dx.doi.org/10.1016/j.apsusc.2014.04.048.

3. Belkhir, N.; Aliouane, T.; Bouzid, D. 2014. Correlation between contact surface and friction during the optical glass polishing, Applied Surface Science 288: 208214.

http://dx.doi.org/10.1016/j.apsusc.2013.10.008.

4. Bo, D.; Jianwei, Z.; Yuling, L.; Mingbin, S.; Yufeng, Z. 2014. Surface roughness of optical quartz substrate by chemical mechanical polishing, Journal of Semiconductors 35: 116001.

http://dx.doi.org/10.1088/1674-4926/35/11/116001.

5. Namba, Y.; Beaucamp, A. T. H.; Matsumoto, A.; Freeman, R. 2011. Fluid Jet and Bonnet Polishing of Optical Moulds for Application from Visible to X-Ray, Proceedings of SPIE 8126. http://dx.doi.org/10.1117/12.905491.

6. Pal, R. K.; Garg, H.; Sarepaka, R. V.; Karar, V.
2016. Experimental investigation of material removal and surface roughness during optical glass polishing, Materials and Manufacturing Processes, 31: 1613-1620. https://doi.org/10.1080/10426914.2015.1103867.

7. Tam, H. Y.; Cheng, H. B.; Wang, Y. W. 2007. Removal rate and surface roughness in the lapping and polishing of RB-SiC optical components, J. of Mat. Proc. Techn. 192-193: 276-280.

http,://dx.doi.org/10.1016/j.jmatprotec.2007.04.091.

8. Bouzid D.; Belkhie, N.; Aliouane, T. 2012. Optical glass surfaces polishing by cerium oxide particles, IOP Conference Series: Materials Science and Engineering 28: 012007. http://dx.doi.org/10.1088/1757-899X/28/1/012007.

9. Lee, J. P.; Hong, K. P.; Cho, M. W.; Kwon, S. H.; Choi, H. J. 2015. Polishing characteristics of optical glass using PMMA-coated carbonyl-iron-based magnetorheological fluid, Smart Mater. Struct. 24: 065002. http://dx.doi.org/10.1088/0964-1726/24/6/065002.

10. Belhir, N.; Chorfa, A.; Bouzid, D. 2016. Compression behavior of polyurethane polishers in optical polishing process, International Journal of Advanced Manufacturing Technology 86: 2595-2601.

http://dx.doi.org/10.1007/s00170-016-8393-y.

11. Park, S. S.; Cho, C. H.; Ahn, Y. 2000. Hydrodynamic analysis of chemical mechanical polishing process, Tribology International 33: 723-730.

PII: S0301- 67 9X( 00 )0 0114-6.

12. Feng, Y.; Cheng, H, Tam, H. Y. 2015. Mapping error correction of large off-axis aspheric surface in null test, 
Optik 126: 5825-5829.

http://dx.doi.org/10.1016/j.ijleo.2015.09.251.

13. Wang, C.; Wang, Z.; Wang, Q.; Ke, X.; Zhong, B.; Guo, Y.; Xu, Q. 2017. Improved semirigid bonnet tool for high-efficiency polishing on large aspheric optics, International Journal of Advanced Manufacturing Technology 88: 1607-1617.

http://dx.doi.org/10.1007/s00170-016-8901-0.

14. Wang, C.; Yang, X.; Zhong, B.; Wang, Z.; Guo, Y.; Xu, Q. 2014. Effect of the inflated-pressure to the tool influence function for polishing using SR bonnet, SPIE Proceedings: 9281. https://doi.org/10.1117/12.2067758.

15. Full Factorial Designs. Available from Internet: https://www.jmp.com/support/help/en/15.1/index.shtml\#page/jmp/full-factorial-designs.shtml\#

N. Kadzevičius, I. Švagždytė, J. Gargasas, M. Jurevičius, A. Kilikevičius

\section{INVESTIGATION OF POLISHING CHARACTERISTICS FOR ASPHERICAL LENSES MANUFACTURING}

S u m m a r y

Spherical lenses were used in conventional industry for a long time, but new types of lenses have been created during the innovation processes. One type of lenses is aspherical. Two main parameters describing the quality of aspherical lenses are accuracy of the form shape and surface roughness. These parameters can be obtained after the last operation - polishing. The technical parameters that have the biggest influence on the form shape and surface roughness were investigated in this experiment, and optimal technical parameters for the polishing process were established. Melted quartz "UVFS" was used in this research, the investigations were carried out according to full factorial design. The five-axis CNC machine Schneider SCPA100 was used for polishing and the profilometer Nanoscan 855 was used for measurements. After the analysis of the results, it was found out that the speed of rotation and penetration depth are the most important factors in the polishing process. To obtain the best shape, it is necessary to use the smallest chosen values of rotation speed and penetration depth, whereas the parameters for surface roughness polishing change conversely. The smallest value of surface roughness $R_{z}$ was $0.06 \mu \mathrm{m}$, and shape deviation was $2.6 \mu \mathrm{m}$. Optimal polishing parameters for the best quality of aspherical lenses are provided.

Keywords: aspherical lenses, form deviation, polishing, surface roughness.

Received November 05, 2019

Accepted October 14, 2020

This article is an Open Access article distributed under the terms and conditions of the Creative Commons Attribution 4.0 (CC BY 4.0) License (http://creativecommons.org/licenses/by/4.0/). 